\title{
Cidadania, subcidadania e opinião pública: uma leitura crítica das mídias brasileiras e portuguesas
}

institucional.us.es/ambitos/

\author{
Simone Antoniaci Tuzzo \\ Universidade Federal de Goiás \\ simonetuzzo@hotmail.com
}

English Version: Citizenship, sub-citizenship and public opinion: a critical essay about the brazilian and portuguese media

\section{Resumo}

Pensar a cidadania além do significado da palavra, analisando criticamente a possível ressignificação criada pelos discursos midiáticos no Brasil e em Portugal. A representação da cidadania na mídia brasileira pode comprometer a compreensão social, recriando a noção do que é ser cidadão, com impacto na opinião pública que se pauta nos discursos midiáticos para sua construção, tendo em vista seu poder de alcance e de produção de sentidos. A construção simbólica em torno do ser cidadão

no Brasil, um país em desenvolvimento e em Portugal, um país desenvolvido também é ponto de reflexão e entendimento desta análise crítica do discurso.

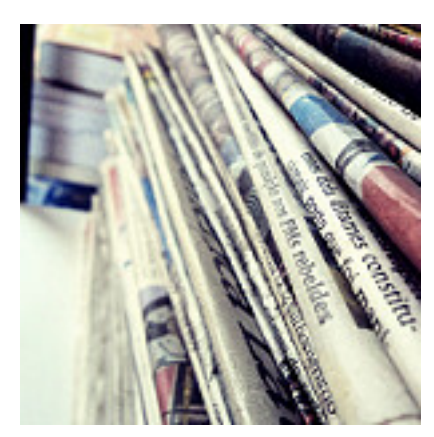

\section{Palavras-Chave}

Cidadania, subcidadania, leitura crítica, mídia, opinião pública.

\begin{abstract}
Think citizenship beyond the meaning of the word, critically analyzing the possible redefinition created by the media discourse in Brazil and Portugal. The representation of citizens in the Brazilian media can undermine social understanding, recreating the notion of being a citizen, with impact on public opinion that is guided in the

media discourse for its construction, given its power to reach and production of meanings. The symbolic construction around the citizen be in Brazil, a developing country and in Portugal, a developed country is also the point of reflection and understanding of this critical discourse analysis.
\end{abstract}

Keywords

Citizenship, undercitizenship, critical reading media, public opinion.

\section{Introdução - Para Continuarmos A Falar De Cidadania}

Este é o segundo momento de uma pesquisa sobre a representação da cidadania a partir de uma leitura crítica da mídia, ou seja, como a mídia se utiliza da palavra cidadania, qual o seu significado no discurso midiático.

ÁMBITOS

2016

$n^{2} 31$

A primeira pesquisa foi realizada no Brasil em 2013, quando Tuzzo (2014) fez um estudo para identificar os sentidos da palavra cidadania pela mídia, ou seja, não se trata de uma abordagem sobre o significado da palavra, mas sim, o uso que se faz dela; como a mídia se apropria do conceito para gerar novos significados, nem sempre explícitos, mas a representação da cidadania pela mídia e o seu impacto na formação da opinião pública.

Para Sodré (2006), esses estudos fazem parte da responsabilidade que se deve ter com um novo pensamento crítico para aquilo que está aquém ou além de um conceito.

No Brasil, o resultado da pesquisa aponta para uma representação da palavra cidadania com o significado de subcidadania, ou seja, a palavra cidadania nos meios de comunicação de massa impressos e eletrônicos 
designa uma condição de subcidadania. A Cidadania aparece ligada ao povo, à pobreza, à precariedade. "A mídia apresenta o conceito de cidadania como algo em busca, o ideal de quem ainda não é cidadão e precisa chegar a essa categoria existencial” (Tuzzo, 2014: 176). A partir do discurso da mídia a autora também identifica que:

"O cidadão é aquele que está na sociedade de forma economicamente privilegiada e pode pagar pela cidadania, comprando saúde, educação, segurança, lazer, por exemplo, ou seja, a cidadania é comprada, é privada, disponível e acessível para quem pode pagar por ela. Assim, cidadania tem a ver com o privado e a busca da cidadania tem a ver com o que é público. Cidadania é a plenitude de existência do rico e a busca constante do pobre" (Tuzzo, 2014: 177).

A busca pela cidadania no Brasil se dá pela falta dos elementos básicos de constituição da cidadania plena de direitos e deveres, ou seja, moradia, transporte, educação, saúde, segurança, lazer e consumo. Se pensarmos nos discursos midiáticos de um País da Europa, onde as representações sociais dos serviços governamentais nomeados acima fazem parte da rotina de qualquer morador de Países Europeus, como a palavra cidadania é utilizada? A motivação desta pesquisa está em descobrir em que termos a palavra cidadania é utilizada em um País onde o Estado arca com o cumprimento dos elementos constitutivos da formação de um indivíduo em cidadão.

Nesta pesquisa realizada em 2014, a ideia é apresentar em que contextos a palavra cidadania é utilizada pela mídia portuguesa. Quais são os significados de cidadania. Partindo da premissa de que a mídia pode dar novo significado às palavras a partir das necessidades ou conveniências sociais, a palavra cidadania nos jornais impressos portugueses sofre conotações diferentes dos sentidos clássicos da cidadania?

Se pensarmos na cidadania plena, podemos nos basear no conceito firmado por Carvalho (2010) que divide a conquista da cidadania em três chaves de direitos: civis, políticos e sociais.

Pinsky (2008) corrobora afirmando que ser cidadão faz referência aos direitos civis, incluindo a liberdade, a vida, a igualdade social, ao direito de possuir propriedades; direitos políticos, como a possibilidade de escolha dos representantes de um determinado local, cidade, país; e os sociais, que diz respeito à saúde, trabalho, transporte, educação, lazer, segurança.

Assim, este trabalho busca identificar se no discurso midiático português a palavra Cidadania é utilizada para identificar esses direitos, ou se a palavra extrapola esses significados e passa a ter uma nova conotação.

Além disso, esta pesquisa também busca identificar se nos discursos midiáticos portugueses é utilizada a palavra cidadania com o significado de subcidadania, no mesmo sentido que a palavra adquire no Brasil, ou seja, de um desejo ou de uma busca pela cidadania.

O estudo da representação da palavra cidadania pela mídia portuguesa poderá reforçar ainda mais o desvio de significado da palavra cidadania no Brasil que, baseado em outros estudos, ganha novos termos, para designar uma cidadania precária.

Carvalho (2010) utiliza o termo estadania para designar a dependência do Estado pelos subcidadãos. A estadania é firmada quando o Estado não arca com suas responsabilidades de segurança, saúde, moradia, transporte, lazer e educação e com isso faz surgir grupos de apoio com privilégios. Os direitos civis, sociais e políticos não são conquistados, mas passam a servir como moeda de troca da elite brasileira, sobretudo em épocas de eleição.

As políticas sociais que deveriam ser incorporadas ao sistema governamental brasileiro, trabalhadas de forma sistemática e contínua; acabam sendo utilizadas como elemento partidário e não de política pública, ou seja, o partido político do gestor que o implantou se declara responsável pelo benefício e exerce pressão ameaçadora diante da população, fazendo os brasileiros acreditarem que se o partido político não for perpetuado no poder, os benefícios sociais serão extinguidos. Isso ficou absolutamente claro nos discursos de reeleição da Presidente Dilma Rousseff do Partido dos Trabalhadores (PT) em 2014, quando a candidata declarava que os benefícios sociais seriam mantidos em seu governo, que criou e implantou programas sociais de moradia e 
ajudas financeiras para famílias carentes, mas que ela não poderia garantir tais benefícios caso saísse do poder. Foi reeleita.

E isso tem impacto direto na forma de construção da opinião pública, tendo em vista que, no exemplo acima citado, a reeleição não foi garantida pela massa, mas sim, pelos públicos com interesses na continuidade do poder, não somente os beneficiados diretos, ou seja, pessoas das classes mais baixas da sociedade, mas públicos de interesse de um sistema de benefícios onde muitos lucram e fazem com que curiosamente a própria desigualdade social atinja níveis nunca antes vistos.

Carvalho (s/d: 339) explica que:

"No caso brasileiro, a centralidade do Estado não indica seu caráter público e universalista. Isto porque, de um lado, o Estado coopta seletivamente os cidadãos e, de outro, os cidadãos buscam o Estado para o atendimento de interesses privados. A expressão estadania, [...] não tem um sentido propriamente cívico, assim como não indica a afirmação civil da cidadania. Parece, portanto, que nosso lugar dentro da tipologia seria melhor definido ao lado da Alemanha [onde] as palavras usadas para indicar a cidadania podem derivar tanto de cidade como de Estado vai na mesma direção que inspirou o conceito de estadania".

Desta forma Carvalho (s/d) reforça a ideia de que no Brasil a cidadania é algo construída de cima para baixo, o que gera imposição e paternalismos.

Mais que isso, a prática de se comprar bens e serviços que garantam a cidadania, como escolas particulares, saúde privada, segurança em condomínios residenciais fechados, carros particulares que ocupam os lugares dos precários (às vezes inexistentes) transportes públicos, faz com que no Brasil haja um reforço da relação entre cidadania e consumo. Cidadão é aquele que também pode participar da cadeia de compras.

O poder de compra é simbólico, o consumo na sociedade moderna é a garantia de ser identificado como cidadão, tendo em vista que só consome quem tem dinheiro e, portanto, faz parte da cadeia de desenvolvimento social e emprego.

Paiva e Sodré (2013), reforçam a ideia, afirmando que o consumo recria o cidadão moderno, principalmente por se tratar de um consumo de aparência, voltado para a glória do consumidor, feito para impressionar o outro. Uma relação que nasce com a elite, mas que se reconstrói nas classes sociais mais baixas da atualidade. Neste sentido, a mídia se coloca como a substituta de uma relação que existia diretamente entre cidadão e Estado e se firma como a interlocutora do processo de interrelação entre cidadão e sociedade. Para Paiva e Sodré (2013: 54), "se funda a cidadania no consumo". Nessa lógica, quem consome é cidadão.

Sobre isso, Canclini (1999) considera que:

"Homens e mulheres percebem que muitas das perguntas próprias dos cidadãos -a que lugar pertenço e que direitos isso me dá, como posso me informar, quem representa meus interesses - recebem sua resposta mais através do consumo privado de bens e dos meios de comunicação de massa do que nas regras abstratas da democracia ou pela participação coletiva em espaços públicos." (Canclini, 1999: 37).

Ainda na relação entre cidadania e consumo, Goidanich (2002) coloca a questão firmada no pertencimento, ou seja, da mesma forma que nascer em um território, exercer as práticas sociais e culturais são elementos constitutivos de pertencimento, o consumir se incorpora e este sentimento de pertença. Textualmente o autor afirma que:

"Qualquer ser humano precisa ter a sensação de pertencer, mas, neste início de século, pertencer representa muito mais do que uma característica familiar ou territorial, passando a ser múltiplo e transnacional, representado pelos bens que consumimos, por nossas preferências e nossos estilos de vida. Isto é, encontramos nossas identidades mais como consumidores globais do que como cidadãos locais." (Goidanich, 2002: 74)

Martin-Barbero (2003: 290) afirma que pensar sobre a prática do consumo é refletir sobre as práticas cotidianas de desigualdades sociais, quer seja na relação com o corpo, quer seja no uso do tempo que é 
distinto para as pessoas, o habitat, a questão da consciência, o que pode ser alcançado ou atingido. Assim, "o consumo não é apenas a reprodução de forças, mas também a produção de sentidos".

Nesta lógica, a mídia como criadora, reforço ou reorganizadora de sentidos apresenta discursos de construção de marcas, por exemplo, atreladas ao pertencimento social, cultural, ideológico, que faz com que pertencer signifique ter e com isso estar atrelado à grupos sociais, um sentido de participação. Nesta mesma lógica, Tuzzo (2014) afirma que a mídia desempenha um papel importante na construção daquilo que é ser cidadão, pois o que a mídia discursa ser cidadania é o que a sociedade compreenderá como realidade.

Textualmente a autora afirma que no Brasil:

A mídia apresenta o conceito de cidadania como algo em busca, o ideal de quem ainda não é cidadão e precisa chegar a essa categoria existencial. Não encontramos a palavra subcidadania nos discursos midiáticos, o que poderia nos levar num primeiro momento a compreender que a mídia não considera a subcidadania. Mas isso seria um erro, porque na verdade a mídia trabalha frequentemente com subcidadania em seus discursos e não com cidadania. Na verdade fala-se a palavra cidadania, mas sempre no sentido de tudo que falta, de um objetivo a ser alcançado. Os conceitos de cidadania são, na verdade, conceitos de subcidadania. O discurso é feito para o subcidadão, sob o título de "busca pela cidadania", a subcidadania encontrou um sinônimo capaz de não chocar os pertencentes a esta categoria. (Tuzzo, 2014: 176).

Nesse pensamento crítico de reflexão sobre os termos cidadania/cidadão, Carvalho (2010) narra a voga que assumiu a palavra cidadania:

Políticos, jornalistas, intelectuais, líderes sindicais, dirigentes de associações, simples cidadãos, todos a adotaram. A cidadania, literalmente, caiu na boca do povo. Mais ainda, ela substitui o próprio povo na retórica política. Não se diz mais 'o povo quer isso ou aquilo', diz-se 'a cidadania quer'. Cidadania virou gente. (Carvalho, 2010: 7)

Dentro de toda esta perspectiva a inquietação também se desenvolve no pensamento sobre o impacto que este processo acarreta na formação da opinião pública, tendo em vista que, se é verdade que os meios de comunicação de massa não são os únicos responsáveis pela formação da opinião pública, não é mentira que o impacto que eles causam com a ampliação de voz que possuem e a credibilidade legitimada é muito grande e muitas vezes fundamental para determinados públicos.

Quando a mídia reorganiza a sociedade em termos de cidadãos ou subcidadãos, ressignificando o papel do Estado e das pessoas, a probabilidade de aceitação sem questionamento é muito grande em uma sociedade com níveis educacionais desprivilegiados e, portanto, muitas vezes sem a possibilidade de interpretação dos discursos.

\section{Metodologia}

Esta pesquisa foi realizada com a mídia impressa e eletrônica portuguesa no período de 01 de janeiro a 31 de dezembro de 2014, quando foram analisados os significados da palavra cidadania e se a mídia trabalha também com o conceito de subcidadania, ou seja, palavras que explicassem o que a mídia apresenta por cidadania.

Quando a mesma pesquisa é feita no Brasil, é comum encontrarmos o termo desejo de cidadania. Considerando que o desejo é uma expressão de falta, desejar cidadania é um reforço de discurso de que ela não existe para todos. Assim, essa também foi uma inquietação sobre a possibilidade desse termo, ou outros semelhantes, ser ou não identificado na mídia de Portugal.

Foram selecionados 11 jornais de Lisboa, sendo 8 comercializados: Expresso; I; Sol; Jornal de Notícias; Correio da Manhã; Público; Diário de Notícias; Jornal de Negócios e 3 de distribuição gratuita, com amplo acesso à população que se utiliza de transportes públicos, como trens, metros e ônibus, quais sejam: Câmara Municipal de Cascais; Destak; Metro. 
O material utilizado foi extraído de jornais impressos e eletrônicos, tendo em vista que boa parte dos conteúdos está hoje também disponibilizado na Internet.

O universo da pesquisa foi composto por 77 textos que apresentavam a palavra cidadania a partir de matérias, notas, artigos, reportagens, opiniões, notícias, crônicas, enfim, o discurso midiático de forma geral atrelado ao conceito de cidadania.

A opção pela mídia impressa se firma na credibilidade que o jornal impresso exerce nos leitores e consumidores de mídia. Comumente o jornal impresso pauta as discussões diárias nos ambientes públicos e privados, sendo referência para a pauta de veículos eletrônicos como a TV, o rádio e a própria internet que iniciam o dia comentando as primeiras páginas de jornal e seus principais conteúdos diários. É comum os portugueses iniciarem o dia nas esplanadas apreciando um café e um jornal. Além disso, com as distribuições gratuitas de jornais nos transportes públicos, é também muito comum as viagens nesses transportes serem feitas com a leitura dos impressos.

Mesmo quando elege-se a plataforma digital para leitura do jornal impresso, a credibilidade do impresso consegue ser transferida para o dispositivo móvel, numa clara relação de fidelidade ao conteúdo do papel, produzido por empresas legitimadas pela sociedade.

É cada vez mais reconhecido que os produtos desta indústria midiática desempenham um papel central na formação de imagens e discursos que orientam nossa percepção do mundo (Golding; Murdock, 2000). A mídia desempenha um papel importante na construção daquilo que é ser cidadão, ou seja, o que a mídia divulga como sendo cidadania é o que a sociedade compreenderá como real. Gracia (2004) complementa esta ideia afirmando que se a linguagem constitui-se num instrumento para representar a realidade, então sua análise pode nos informar sobre a natureza dessa mesma realidade".

Aqui não está descartada a hipótese da realidade ser também uma representação midiática com credibilidade. Sobre isso Sodré (2009) afirma que "o texto de jornal representa basicamente um tipo de intervenção na língua - com os recursos retóricos da clareza e da concisão - afinado com a estrutura ideológica do sistema informativo, cuja forma mais evidente é a presumida transparência da realidade, por meio da evidência noticiosa dos fatos. É, porém, uma presunção que esconde as refrações, as distorções e a mística do que se pretende erigir como espelho do real."

A opção pela análise de discurso se pauta por sua característica de:

"Produzir enunciados teóricos, científicos, portanto lógicos acerca da realidade, a partir da sua observação subjetiva [...] ter ciência de alguma coisa significa, portanto, ser capaz de recortar no tempo e de separar no espaço a complexidade da realidade, tornando-a acessível por um discurso metódico" (Trigo, 2011: 285).

Como categoria de método empírico, a análise de discurso pode ser descrita como:

"Análise qualitativa, por vezes crítica, do discurso jornalístico, surja este como texto, imagens, sons, multimédia ou hipermédia. Englobaram-se nessa categoria metodológica, as análises semióticas e psicanalíticas do discurso jornalístico, a análise conversacional e a análise linguística (títulos e notícias)" (Sousa, 2011: 314).

Sousa (2003) ainda complementa afirmando que: "A análise do discurso é um dos métodos científicos mais utilizados em ciências da comunicação. É muito empregue, por exemplo, para analisar conteúdos de jornais [...] a análise de discurso pode ser aplicada isoladamente ou em conciliação com outros métodos."

Importante destacar que conforme afirma Resende e Ramalho, "o discurso é tanto um elemento da prática social que constitui outros elementos sociais como também é influenciado por eles, em uma relação dialética de articulação e internalização" (Resende; Ramalho, 2006: 39).

Para Correia (2008), a análise do discurso pode ser caracterizada como um enfoque da linguagem que envolve também os níveis lexical, semântico, retórico e estilístico. Para o autor a análise de discurso também se preocupa com os significados locais, o estilo e a relação com o contexto de produção e de recepção. Assim, é 
sempre importante se preocupar com as práticas sociais ideológicas de produção de um discurso.

Van Dijk (2010) vai além afirmando que "a Análise Crítica do Discurso (ACD) é um tipo de investigação analítica discursiva que estuda principalmente o modo como o abuso do poder, a dominação e a desigualdade são representados, reproduzidos e combatidos por textos orais e escritos no contexto social e político".

A leitura crítica da mídia e a análise crítica de discurso adotadas para esta pesquisa estão pautadas nos estudos da Escola de Frankfurt. Para Temer e Nery (2009: 85), "O Paradigma Crítico Radical está intimamente ligado às reflexões sobre cultura desenvolvidas pela filosofia clássica alemã". Para Thompson (1995: 135) "a análise da indústria cultural feita por Horkheimer e Adorno (integrantes da Escola de Frankfurt), representa uma das tentativas mais corajosas realizadas por teóricos sociais e políticos para compreender a natureza e as consequências da comunicação de massa nas sociedades modernas".

Freitag (1990) afirma não haver dúvida de que o pensamento crítico da Escola de Frankfurt permanece vivo, virulento e polêmico como nunca, e por isso exige fidelidade às origens, mas também sugere uma renovação.

Para Tuzzo (2014) essa releitura, bem como a investigação da produção científica na área da comunicação, contribui para a concepção de um método de análise crítica da produção midiática nos dias atuais sobretudo voltados para os estudos da mídia em suas várias manifestações. Nesta proposta de pesquisa, portanto, o ponto de partida é o entendimento da crítica como possibilidade de re-descobrir - o lançar um novo olhar mais profundo, que permita desconstruir a realidade e a partir daí lance bases para propostas de transformação.

Dessa forma, parte-se de um processo de teorização do problema a partir do que a questão central apresenta como centro investigativo. Neste caso, a Mídia e a Cidadania são pontos de partida de uma interlocução para se pensar a questão central: "O que é cidadania no discurso midiático?".

A dinâmica de uso da comunicação estratégica e simbólica que se faz pela linguagem semiótica é também um elemento fundamental para podermos chegar ao atual estágio de desenvolvimento da humanidade. Em tempos de internet, os conteúdos e sua recepção são entendidos como compreensão de sentidos cujo tema é profundamente estudado por Kerckhove (2009) e Sodré (2006).

Assim, o estudo dos processos comunicativos mediados e midiatizados é essencial para a compreensão da dinâmica das relações humanas. Para Sodré (2006), a sociedade da cultura implica em um cultivo das possibilidades sensoriais em busca de um sentido emancipatório, diante da hegemonia mercadológica da mídia transnacional. Ainda segundo o autor, o desafio epistemológico e metodológico da comunicação é gerar uma compreensão e uma aplicação do que se conhece, a fim de que os participantes do discurso possam orientarse nas situações concretas da vida pelo sentido comunicativamente obtido.

Com base nessas afirmações podemos pensar que a leitura crítica da mídia se faz necessária para que a ideia de um discurso legitimado pela mídia possa ser questionada, analisada e não consumida sem apreciação. Afinal a língua é viva, sujeita a transformações em cada cultura e uma palavra pode sofrer modificações de uso com o tempo, com a dinâmica social, com as apropriações hegemônicas e contra hegemônicas ao longo de sua utilização.

\section{O significado da cidadania no discurso midiático português}

$\mathrm{Na}$ análise de discurso da mídia portuguesa a palavra cidadania é usada majoritariamente para designar nacionalidade, ou seja, aquele que nasceu em um determinado País; que é natural de algum lugar. O Jornal de Notícias do mês de fevereiro apresenta uma matéria onde a palavra cidadão designa os nascidos na Síria: "Os cidadãos sírios são os principais responsáveis pelo aumento de massa de refugiados. No último ano, houve cerca de três milhões de sírios que atravessaram as fronteiras da Síria para os países vizinhos (Líbia, Turquia, Iraque e Jordânia) e 6.5 milhões de deslocados pelo território".

Ou ainda o Jornal Público que em janeiro de 2014 publicou o texto que faz referência aos nascidos em dois 
países europeus: "Sete anos depois da adesão de Roménia e Bulgária à União Europeia, os nove países que ainda mantinham restrições no acesso dos cidadãos dos dois países aos seus mercados de trabalho Alemanha, Áustria, Bélgica, Espanha, França, Reino Unido, Luxemburgo, Malta e Holanda - tiveram de Ihes pôr um fim".

Na mesma linha, o Jornal Sol, em outubro de 2014 afirmou que "no ano passado, mais 296 mil emigrantes registraram-se nos consulados de 20 países com maiores comunidades portuguesas. No total já são 3,8 milhões os cidadãos lusos que vivem fora do País".

Em Portugal, assim como na Itália e outros países da Comunidade Europeia, Cidadão é aquele que nasce no país, legalmente considerado do solo, que vem do latim jus soli e por isso lhe é determinado o direito a viver no solo em que nasceu. Mas também há outra forma de classificar-se como cidadão Português que é o direito de sangue, derivado do latim jus sánguinis, ou seja descendente de Português que apesar de não ter nascido em solo Luso, possui o direito à nacionalidade, ou cidadania portuguesa.

Este princípio de reconhecimento da cidadania pelo sangue tem explicação e respaldo devido à grande migração de europeus nos séculos XIX e XX, época de recessão na Europa e incentivo à imigração, sobretudo para os países da América.

Após a estabilização da Europa, governos de algumas nações reconhecem o direito de sangue, justificando que essas pessoas poderiam ter nascido na Europa e se isso não ocorreu não foi por vontade dos ascendentes, mas por uma necessidade de sobrevivência e de busca feita por seus ascendentes por melhores condições de vida em outros Países.

Desta forma, quem nasce ou quem é descendente de Portugueses possui o direito à cidadania do País.

Esta compreensão que vincula o direito à cidadania à territorialidade ou mesmo à parentalidade, com algum sujeito nascido em determinada terra esteve presente na história da humanidade desde as primeiras civilizações sedentárias. Segundo Gorzeviscki e Martin (2011) isso era necessário para delimitar e distinguir os agrupamentos sociais, concebendo deste modo as noções pioneiras de política.

A compreensão do verbete cidadania foi orientada por questões geográficas e sanguíneas até que Marshall (1967) passou a analisar a dissonância entre os indivíduos que habitavam a cidade e se submetiam à profundas desigualdades sociais que propiciavam o acesso a direitos apenas por alguns. Em sua visão, o pertencimento à um território não representava o encontro automático e pleno de direitos, e assim passou a advogar em favor de um conceito que incluísse na cidadania a aglutinação de direitos políticos, civis e também sociais, cujo rol de garantias previa acesso a bens materiais, educação, habitação, entre outras condições básicas de vida.

Encontra-se com grande freqüência em textos da mídia a palavra cidadão ou cidadania para designar o oriundo de alguma localidade. Também é utilizada a palavra cidadão ou cidadania quando a mídia se refere às atividades disponibilizadas pela Loja do Cidadão, ou seja, um espaço físico mantido pelo Governo Português para prestação de serviços aos cidadãos no tocante a documentos e serviços.

O Jornal de Negócios, em julho de 2014, divulgou uma matéria que ilustra essa situação: "O ministro-adjunto e do Desenvolvimento Regional apontou como meta até 2020 a total digitalização da Administração Pública, com uma loja do cidadão por município apoiada por uma rede complementar de Espaços do Cidadãos e soluções de mobilidade".

A palavra cidadão também é identificada nos discursos eleitorais, para designar o eleitor, numa clara relação do direito ao voto que o cidadão europeu possui. A matéria publicada no Jornal de Notícias do mês de maio de 2014, após as eleições europeias é um exemplo desse discurso: "As eleições europeias foram decepcionantes, por muito previsível e bem merecido que seja o duro castigo infligido pelos cidadãos europeus à manifesta incompetência exibida pelo governo da União na gestão da crise da moeda única, nos últimos quatro anos!"

O Jornal Público também publicou em maio de 2014 uma matéria onde isso pode ser verificado: "Emigrantes 
portugueses do município de Breckland, no leste do Reino Unido, alegam terem sido impedidos de votar nas eleições para o Parlamento Europeu de quinta-feira por questões burocráticas. Segundo a Comissão Eleitoral, os cidadãos da União Europeia (UE) podem votar para as autoridades ou organismos locais, mas não para o Parlamento Europeu."

Além das eleições, as palavras cidadão ou cidadania podem ser verificadas em discursos que envolvam a política de uma forma geral, como neste comentário do ex-deputado Henrique Neto, divulgado em maio de 2014 pelo Jornal Expresso: "Não creio que o plafonamento resolva o problema da sustentabilidade de um sistema que, por força da atuação arbitrária do governo, deixou de merecer a confiança dos cidadãos".

Numa relação de direito do cidadão, o Jornal Destak do mês de junho de 2014 traz uma matéria sobre o Google no seguinte contexto: "Depois da decisão da justiça europeia, que dá aos cidadãos o direito ao esquecimento digital, a Google disponibilizou um formulário online para os interessados em ver informações suas eliminadas da internet".

Contudo, nos textos jornalísticos portugueses é comum o uso das palavras: mulher, homem, criança, jovem, estudantes, trabalhadores, população, pessoas da cidade, consumidores, munícipes, moradores, utentes, habitantes, enfim, palavras que no mesmo contexto no discurso jornalístico brasileiro são costumeiramente trocadas por cidadão.

Mesmo em matérias que fazem alusão às catástrofes e desgraças humanas como problemas de enchentes, segurança, saúde, inundações, o termo para designar os atingidos é pessoas. Para a mídia trata-se de pessoas sem abrigo ou com problemas, conforme pode ser visto na matéria do Jornal Público de fevereiro de 2014 "Há cada vez mais sem-abrigo num país com um milhão de casas vazias. Impossível adiantar quantas pessoas estão sem casa, muito menos quantas a têm clandestina, como aquela rapariga que até já vendeu o cadeado que o amigo metera na porta. Na Estratégia Nacional para a Integração de Pessoas Sem Abrigo, aprovada em 2009, consta a promoção do conhecimento sobre o fenómeno. O Instituto de Segurança Social, porém, não esclarece quantas se encontram nesta situação".

Em notícias sobre distúrbios de transporte como as greves de trens e metrô, os termos mais utilizados são trabalhadores, usuários, passageiros ou clientes, mas não cidadãos. O Jornal Diário de Notícias em dezembro de 2014 divulgou a matéria sobre distúrbios com os comboios nos seguintes termos: "Um comboio ficou hoje retido no apeadeiro da Aveleda, em Braga, devido a confrontos entre passageiros, disse hoje à Lusa fonte da CP.O comboio, que seguia no sentido Braga-Porto, ficou retido na Aveleda, para que a polícia pudesse tomar conta da ocorrência, adiantou a mesma fonte".

Nos textos midiáticos sobre educação também não é identificada a palavra cidadão. Nesse contexto a mídia refere-se às pessoas como crianças ou adolescentes em idade escolar ou estudantes, conforme pode ser verificado na matéria divulgada no Jornal Diário de Notícias de junho de 2014: "Uma em cada cinco crianças em idade escolar usa óculos, devido, entre outras causas, ao aumento de tarefas e uso de computadores, disse hoje o oftalmologista Paulo Vale, alertando para a importância dos rastreios a partir dos três anos".

Em outras situações como assaltos, crimes ou problemas sociais, verifica-se o uso dos termos: portugueses detidos; pessoas revoltadas; moradores que reivindicam, mas não se identifica a palavra cidadão ou cidadania. Neste sentido, o Jornal Público divulgou uma matéria em maio de 2014 com o caráter de preservação da memória do 25 de Abril que trazia o seguinte conteúdo: "Vivia-se em pleno frenesim revolucionário pós-25 de Abril, e várias equipas de arquitectos - entre consagrados, jovens e estudantes - foram mobilizadas para as diferentes regiões do país, onde se lançaram a fazer projectos com a participação e em diálogo directo com as populações. Os arquitectosprojectavam, os moradores construíam, o Estado pagava os materiais...".

Nas informações sobre saúde a palavra mais encontrada na mídia é utente, que significa usuário. Se a referência é para problemas de saúde os termos utilizados também são: infectados ou doentes. Como exemplo, o Jornal Diário de Notícias no mês de janeiro de 2014 trouxe o seguinte texto: "Os centros de saúde vão começar a avaliar a satisfação dos utentes este ano e vão receber prémios pelo cumprimento de metas na área, pela primeira vez, e com um peso de $5 \%$ entre os indicadores a avaliar". 
O Jornal Correio da Manhã de dezembro de 2014 publicou: "As cirurgias a doentes com tumores malignos aumentaram $2 \%$ no primeiro semestre de 2014 , tendo sido operados mais 457 utentes do que em igual período de 2013, segundo o Ministério da Saúde".

Mesmo quando a mídia refere-se a território, ou seja, literalmente o cidadão, também se apropria de outros termos como membro de uma localidade ou até em situações de problemas utiliza-se a palavra refugiado, conforme pode ser constatado no trecho a seguir da matéria publicada na edição especial do Jornal Público 2014 "No final de 2013 tínhamos mais de 51 milhões de pessoas internamente deslocadas ou refugiadas por causa de conflitos, o que aconteceu pela primeira vez desde a II Guerra Mundial. Só que 2014 não vai ser melhor. Vou dar-Ihe apenas uma breve descrição de alguns dos acontecimentos que tivemos de enfrentar no Alto Comissariado das Nações Unidas para os Refugiados (ACNUR). Logo no princípio do ano houve o agravamento dramático da situação na República Centro-africana e no Sudão do Sul".

A seguir serão apresentadas as principais conclusões da pesquisa.

\section{Conclusões}

A partir da análise crítica do discurso midiático Português, verifica-se que as palavras cidadania ou cidadão são utilizadas majoritariamente com o significado clássico, que designa direitos e deveres.

Quem nasce ou quem é descendente de Portugueses possui o direito à cidadania do país e a palavra cidadania na mídia portuguesa é utilizada principalmente para designar as características de nacionalidade tanto de Portugal, quanto de qualquer outro país.

Em Portugal a palavra cidadania não é banalizada, não é utilizada aleatoriamente e muito raramente é utilizada em conceitos diferentes do significado de oriundo do país ou para designar assuntos relacionados à política.

Se compararmos com o Brasil, onde a palavra cidadão é utilizada como sinônimo de mulher, homem, criança, jovem, estudante, trabalhador, população, pessoas da cidade, consumidores, munícipes, moradores, habitantes, ou seja, onde existe uma vulgarização da palavra, pode-se verificar que em Portugal isso não ocorre.

Dentro de uma reflexão linguística e da própria análise discursiva é possível afirmar que as palavras, ao constituírem seus enunciados carregam potenciais capacidades de portar em seus sentidos as marcas sociais dos meios aonde se inscrevem. Benetti (2010) assevera que nenhum discurso é ingênuo e por isso defende que as palavras apresentam implícitas e imbricadas em seus conceitos, camadas ideológicas que as atrelam ao contexto histórico, político e social.

Partindo desta ideia é possível afirmar que no Brasil, em vistas de sua trajetória histórica e atual conjectura, a palavra cidadania traga envergada em si uma nítida ideia de conflito, reflexo das inúmeras tensões sociais que se permeiam na realidade do país. Ao passo que o europeu tenha adquirido sua cidadania enquanto garantias e direitos, a menção do termo no sentido de pressionar a esfera política não se faz necessária uma vez que não existe ruptura, ao contrário do Brasil onde a realidade inversa se realiza.

Motta (2010: 164) esclarece que o discurso midiático pressupõe o agendamento de rupturas. "Os jornalistas só destacam certos fatos da realidade como notícia porque estes fatos transgridem algum preceito ético, moral, alguma lei ou consenso cultural. A notícia representa sempre a ruptura ou transgressão a algum significado estável". Logo, dentro da circunstância portuguesa, onde a cidadania enquanto direitos políticos, civis e sociais já seja uma realidade empírica não há sentido utilizar o termo fora de seu conceito original, desprovido de tensões contextuais. O termo cidadania possui seu significado estável possivelmente inabalado.

Já no Brasil a palavra cidadania é o vértice de inúmeras transgressões legais, culturais, éticas e morais e por sua inexistência em sentido pleno, como postulava Marshall (1967) traz em sua enunciação todo movimento cíclico dentro da sociedade, e que por ser ausente justifica ser mencionada nos relatos que a questionam, provocam, confundem e expõem os reflexos de sua falta. 
Carvalho (2010) já havia colocado o quanto a ideia de cidadania no Brasil ressoava a dependência política, que segundo o autor se devia ao fato dos direitos políticos terem sido os primeiros a serem atingidos no país, tornando os seguintes dependentes da esfera governamental. O que se percebe na atualidade é uma manutenção desta realidade de submissão ao crivo estatal.

No Brasil em várias situações a mídia utiliza a palavra cidadão, inclusive a busca pela cidadania que também se utiliza da palavra cidadão em referência à algo que falta para sua plenitude existencial. Condição também não verificada na mídia portuguesa.

Se um dos elementos constitutivos da cidadania hoje é também o direito ao consumo, como afirmam autores como Baudrillard (1991) e Canclini (1999), a desigualdade econômica tem relação direta com a ideia de autoafirmação pela compra, o que faz com que alguns possam se sentir mais cidadãos do que outros, com base nos bens tangíveis e intangíveis que podem ser adquiridos a partir do dinheiro. Sobre isso a mídia também está presente com discursos que incentivam a compra e o pertencimento em determinados grupos sociais a partir do consumo. Neste sentido podemos pensar numa relação de cidadãos, subcidadãos e supracidadãos.

Essa discussão não é recente e possui algumas leituras. Para alguns autores o Estado deve garantir a esperança de uma vida melhor, mas não necessariamente oferecê-la pois a existência das classes baixas é responsável pela manutenção de um sistema social. Por isso o assistencialismo é a garantia do status quo, necessário para o equilíbrio social. Para outros, essa ideia não mantém um equilíbrio, mas desestabiliza a sociedade e gera, entre outros problemas, as graves situações de violência urbana.

Autores como Tuzzo (2014), Souza (2011) e Canclini (1999) já tratavam do elo entre os conceitos cidadania e consumo. Nesta linha de pensamento, nas sociedades capitalistas onde imperam as desigualdades sociais e a pouca assistência estatal às necessidades públicas ligadas aos cidadãos, emerge um mercado de direitos compráveis que intensificam a distinção estamental e aprofundam as distâncias econômicas entre os cidadãos, e lógico, a obtenção de direitos.

Assim, educação, saúde, segurança, educação, entre outros, que teoricamente seriam encargo dos governantes de determinado país para com seus habitantes, passa a ser adquirida por aqueles que podem pagar por isso. Aos que não possuem condições monetárias de consumir estes direitos só restam duas alternativas: aguardar e pressionar o governo para receber os direitos ainda que de modo precário, ou corroer as barreiras sociais com alternativas extremas como a violência e o crime. Em especial na última hipótese, temos a exposição de todos os viventes da sociedade aos riscos implicados nestas ações e a figura do Estado aparece como essencial para manter a ordem entre os indivíduos e até mesmo para retirar do convívio público aqueles que a perturbam.

Assim, podemos concluir que a conquista da cidadania plena é dependente do desenvolvimento das políticas públicas, pois mesmo aqueles que possuem um poder aquisitivo maior, também precisam das políticas governamentais para viver em uma sociedade mais equilibrada, mais digna e sem graves problemas que a falta dos elementos constitutivos da cidadania acarretam e atingem pessoas de todas as classes sociais. Com relação à este aspecto, a mídia possui poder de influência na formação da opinião pública e na recriação simbólica de que a garantia de cidadania plena só afeta uma parte da sociedade, pois os de maior poder aquisitivo podem pagar por bens e serviços. Isso é um grande equívoco, com prejuízos para todos os cidadãos. Basta pensar em segurança pública, por exemplo.

Ainda que em Portugal também existam problemas de moradia, transporte, educação, saúde, segurança, lazer e consumo, os benefícios apresentados pelos governantes são maiores do que as dificuldades e os cidadãos podem usufruir desses serviços em seu dia-a-dia, sem ter que adquiri-los a partir de organizações privadas, ou seja, a compra pelos itens constitutivos da cidadania.

Importante destacar que os direitos e deveres constitutivos da cidadania, respaldados e garantidos pelo Estado não deveriam ser confundidos com assistencialismo, como normalmente acontece no Brasil. Essa ideia se respalda nas desigualdades sociais, pois a partir do nível sócio econômico de cada cidadão, a expectativa por 
ações governamentais é modificada. A desigualdade, que concentra nas mãos de poucos a riqueza de uma nação, acarreta níveis de pobreza e miséria que levam a uma dependência de benesses do Estado, mas isso tem conseqüências em todo o conjunto de pessoas habitantes da localidade e não somente nos mais necessitados. A cidadania também deve ser firmada no equilíbrio da sociedade.

Em locais onde a cidadania já seja conferida à população de modo holístico em direitos e deveres não se faz provável a ideia de direitos "comerciais". Não parece lógico pagar de modo privado por algo que já seja assegurado pelo governo no recolhimento de impostos que são investidos nas devidas requisições sociais.

Marshall (1967) quando teorizou sua cidadania plena, direcionou expressivo destaque ao direito social da Educação, afirmando que o acesso aos mecanismos de formação intelectual seria sempre determinante para o acesso e bom uso dos demais direitos. Se considerarmos que toda uma população tenha condições de se instruir em uma mesma estrutura de ensino, se desmantelam boa parte das lacunas sociais que acometem muitas sociedades onde isso não ocorre.

No Brasil os elementos constitutivos da cidadania são privados, ou seja, o transporte baseado em caminhões e automóveis e não em trens, metrôs, ônibus, bondes; a saúde firmada em convênios médicos e não em clínicas e hospitais públicos; o lazer em locais de acesso privado e não a manutenção de espaços públicos; a segurança que obriga a população a residir em condomínios fechados, possuir carros blindados, viver cercada por câmeras e dispositivos de vigilância monitorados por empresas privadas; além do item mais marcante e que poderia ser considerado o responsável pelos demais problemas sociais que é a educação paga pelos pais quando criança ou pelos próprios estudantes quando mais velhos para que tenham um ensino de qualidade, mas, sobretudo, para que possam ter segurança dentro do estabelecimento de ensino que, em muitos casos, tornam-se ambientes insalubres. Estudar em escolas privadas tem relação com o nível educacional, mas também uma relação direta com a segurança, o que agrava o processo.

Essa discussão pode ser encontrada também em Portugal, ainda que em menor escala, mas com tendências de um alerta para que isso não se torne um problema como o que ocorre no Brasil ou em outros países em desenvolvimento. O Jornal Correio da Manhã em uma das matérias do mês de junho de 2014 afirmou que "o PS (Partido Socialista) acusou o Governo de insensibilidade social e de incapacidade em perceber que atrás de cada corte cego na proteção social há um cidadão a precisar de um Estado que combate as desigualdades sociais."

Ou ainda na mesma linha o Jornal Diário de Notícias no mês de abril de 2014 publicou: "Não toleraremos que os nossos cidadãos ainda sejam obrigados a ser duplamente tributados quando estão doentes, por haver quem mine a eficiência e rapidez do SNS (Sistema Nacional de Saúde) por dentro.

A busca pela cidadania no Brasil se dá pela falta dos elementos básicos de constituição da cidadania plena de direitos e deveres. No Brasil a cidadania tem que ser comprada, disponível para quem pode pagar pelos serviços que em países como Portugal, são garantidos pelas políticas públicas, como ensino, saúde, lazer, transporte e segurança... e isso pode ser verificado a partir da comparação dos discursos midiáticos dos dois países.

Desta forma, podemos concluir também que o discurso da mídia Portuguesa reafirma o desvio de significado, ou o ressignificado das palavras Cidadania e Cidadão no discurso da mídia Brasileira. Podemos assim compreender a diferença de percepção do termo implicada por realidades antagônicas de prática social.

Não apenas na superfície da palavra mas em seu âmago simbólico, a diferença dos conceitos não apenas se dá no aspecto da significação linguística do verbete, mas também na presença (ou não) das marcas sóciohistóricas que distanciam os dois países em aspectos muito além dos geográficos e territoriais, e que perpassam o reconhecimento e concretização da cidadania.

\section{Referências Bibliográficas}


BAUDRILLARD, Jean. (1991): A sociedade do consumo. Lisboa: Edições 70.

BENETTI, M.: Análise do discurso em jornalismo: estudo de vozes e sentidos. En: LAGO, C.; BENETTI, M. (Orgs.). (2010): Metodologia de pesquisa em jornalismo. Petrópolis, RJ: Vozes.

CANCLINI, N. G. (1999): Consumidores e cidadãos. Rio de Janeiro: UFRJ.

CARVALHO, J. M. (2010): Cidadania no Brasil: o longo caminho. Rio de Janeiro: Civilização Brasileira.

- (s/d): "Cidadania: Tipos e Percursos", Revista Lua Nova - Cultura e Política, publicada pelo Centro de Estudos de Cultura Contemporânea - CEDEC [on line]. [Acesso em: 12 de outubro de 2015].

<http://bibliotecadigital.fgv.br/ojs/index.php/reh/article/viewFile/2029/1168.> pp. 337-359

CORREIA, J. C.: Os estudos jornalísticos em Portugal: 30 anos de História. En: SOUZA, J. P. (Org.). (2008): Jornalismo, História, Teoria e Metodologia: Perspectivas Luso-Brasileiras. Porto: Edições Universidade Fernando Pessoa. pp. 12- 92.

FREITAG, B. (1990): A teoria crítica: ontem e hoje.São Paulo: Editora Brasiliense.

GOIDANICH, M. E. Mídia, cidadania e consumo: estamos formando consumidores ou cidadãos? En: BELLONI, M. L. (Org). (2002): A formação na sociedade do espetáculo. São Paulo: Loyola.

GOLDING, P.; MURDOCK, G.: Culture, communication and political economy. En: CURRAN, J; GUREVITCH, M. (orgs). (2000): Mass media and society. Londres: Arnold.

GORZEVSCKI, C.; MARTIN, N. B. (2011): A necessária revisão do conceito de cidadania. Santa Cruz do Sul: EDUNISC.

GRACIA, T. I.: O "giro linguístico". En: IÑIGUEZ, L. (coordenador). (2004): Manual de análise do discurso em ciências sociais. Petrópolis, RJ: Vozes.

KERCKHOVE, D. (2009). A pele da cultura. São Paulo: Annablume.

MARTIN-BARBERO, J. (2003): Dos meios às mediações. Rio de Janeiro: Editora UFRJ.

MARSHALL, T. H. (1967): Cidadania, classe social e status. Rio de Janeiro: Zahar. p. 57-114.

MOTTA, L. G.: Análise pragmática da narrativa jornalística. En: LAGO, C.; BENETTI, M.(orgs.).(2010): Metodologia de pesquisa em jornalismo. Petropolis, RJ: Vozes.

PAIVA, R.; SODRÉ, M.: Afeto e mobilidade nas megacidades: o comum e as alternativas de comunicação. En: BARBOSA, M.; MORAIS, O. J. de. (Orgs). (2013): Comunicação em tempos de redes sociais. São Paulo: Intercom.

PINSKI, J.: História da Cidadania. En: Pinsky, J.; Pinsky, C. (Orgs.).(2008): História da Cidadania. São Paulo: Contexto.

RESENDE, V. de M.; RAMALHO, V. (2006): Análise de discurso crítica. São Paulo: Contexto.

SODRÉ, M. (2006): As estratégias sensíveis: Afeto, mídia e política. Petrópolis-RJ: Vozes.

- (2009): A narração do fato: notas para uma teoria do acontecimento. Petrópolis, RJ: Vozes.

SOUZA, J. (2003): A Construção Social da Subcidadania: Para uma Sociologia Política da Modernidade Periférica. Belo Horizonte: Editora UFMG.

SOUSA, J. P.: Quem tem medo da pesquisa empírica? Seguramente, não os pesquisadores portugueses em jornalismo. En BARBOSA, M.; MORAIS, O. J. (2011): Quem tem medo da pesquisa empírica. São Paulo: Intercom. pp. 305-321. 
- (2003): Elementos de teoria e pesquisa da comunicação e dos media. Porto: Edições Universidade Fernando Pessoa.

TEMER, A. C. R. P.; NERY, V. C. A. (2009): Para Entender as Teorias da Comunicação. Uberlândia: EDUFU.

THOMPSON, J. B. (1995): Ideologia e cultura moderna: teoria social crítica na era dos meios de comunicação de massa. Petrópolis, RJ: Vozes.

TRIGO, S.: Ciências empíricas: método, mutabilidade teórica e nova gramática da comunicação científica. En BARBOSA, M.; MORAIS, O. J. (2011): Quem tem medo da pesquisa empírica. São Paulo: Intercom. pp. 283303.

TUZZO, S. A. (2005): Deslumbramento Coletivo: Opinião Pública, Mídia e Universidade. São Paulo: Annablume.

- (2014): O lado Sub da Cidadania a partir de uma leitura crítica da Mídia. En PAIVA, R.; TUZZO, S. A. Comunidade, mídia e cidade: Possibilidades comunitárias na cidade hoje. UFG/FIC. Goiânia.

VAN DIJK, T. A. (2010): Discurso e Poder. São Paulo: Contexto.

\section{Páginas WEB}

Jornal Público [on line]. [Acesso de janeiro a dezembro de 2014]. <http://www.publico.pt> Jornal Sol [on line]. [Acesso de janeiro a dezembro de 2014]. <http://expresso.sapo.pt> Jornal de Negócios [on line]. [Acesso de janeiro a dezembro de 2014]. <http://www.jornaldenegocios.pt> Jornal de Notícias [on line]. [Acesso de janeiro a dezembro de 2014]. <http://www.jn.pt> Jornal Expresso [on line]. [Acesso de janeiro a dezembro de 2014]. <http://expresso.sapo.pt> Jornal Destak [on line]. [Acesso de janeiro a dezembro de 2014]. <http://www.destak.pt> Jornal Diário de Notícias [on line]. [Acesso de janeiro a dezembro de 2014]. <http://www.dn.pt> Jornal Correio da Manhã [on line]. [Acesso de janeiro a dezembro de 2014]. <http://www.cmjornal.xl.pt>

\section{BIOGRAFIA}

Simone Antoniaci Tuzzo é Professora Efetiva do programa de Pós-Graduação em Comunicação da Faculdade de Informação e Comunicação da Universidade Federal de Goiás-UFG. Doutora em Comunicação pela UFRJ, Mestre e Graduada em Comunicação pela UMESP, Coordenadora do Projeto de Pesquisa Rupturas Metodológicas para uma leitura crítica da Mídia entre os Programas de Pós-Graduação da UFG e UFRJ, que integra a ação transversal $n^{\circ}$ 06/2011-Casadinho/Procad.

Ámbitos. Revista Internacional de Comunicación, n.31, edición de invierno, 2016.

Recibido: 26/03/2015

Aprobado: 25/04/2015 